\title{
UNDERSTANDING THE MICROSTRUCTURE AND PROPERTIES OF COMPONENTS FABRICATED BY LASER ENGINEERED NET SHAPING (LENS)
}

M. L. Griffith*, M. T. Ensz*, J. D. Puskar*, C. V. Robino*, J. A. Brooks**, J. A. Philliber**, J. E. Smugeresky**, $† W$. H. Hofmeister

*Sandia National Laboratories, Albuquerque, NM 87185

**Sandia National Laboratories, Livermore, CA 94551

†Vanderbilt University, Department of Chemical Engineering, Nashville, TN 37235

\section{ABSTRACT}

Laser Engineered Net Shaping (LENS) is a novel manufacturing process for fabricating metal parts directly from Computer Aided Design (CAD) solid models. The process is similar to rapid prototyping technologies in its approach to fabricate a solid component by layer additive methods. However, the LENS technology is unique in that fully dense metal components with material properties that are similar to that of wrought materials can be fabricated. The LENS process has the potential to dramatically reduce the time and cost required realizing functional metal parts. In addition, the process can fabricate complex internal features not possible using existing manufacturing processes. The real promise of the technology is the potential to manipulate the material fabrication and properties through precision deposition of the material, which includes thermal behavior control, layered or graded deposition of multi-materials, and process parameter selection.

\section{INTRODUCTION}

Direct laser metal deposition processing is a promising manufacturing technology, which could significantly reduce the length of time between initial concept and finished part. To facilitate adoption of this technology in the manufacturing environment, further understanding is required to ensure routine fabrication of robust components with desired material properties. This requires understanding and control of the material behavior during part fabrication. This paper describes our research to understand solidification aspects, thermal behavior, and material properties for laser metal deposition technologies.

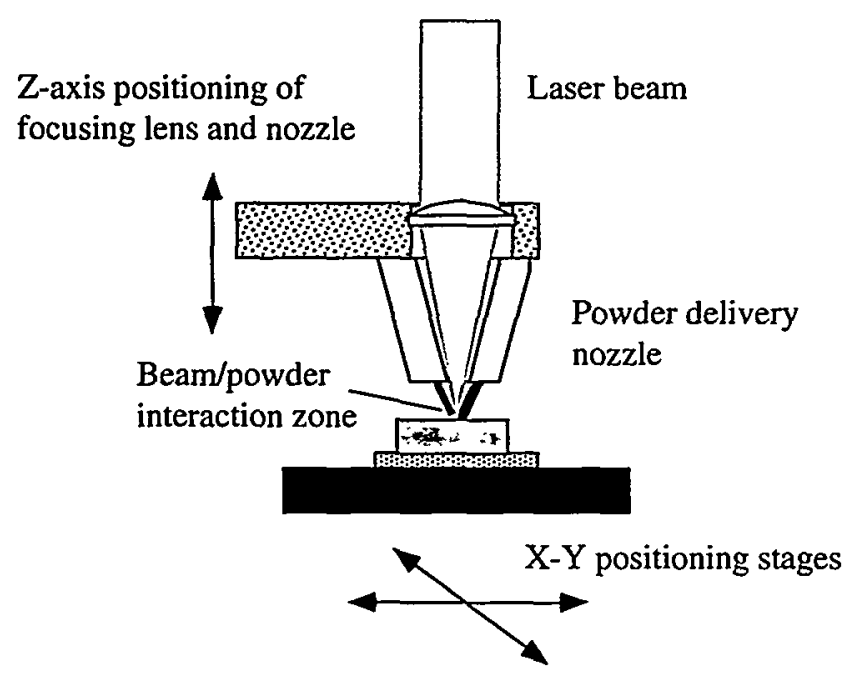

Figure 1: (a) Schematic of LENS process.

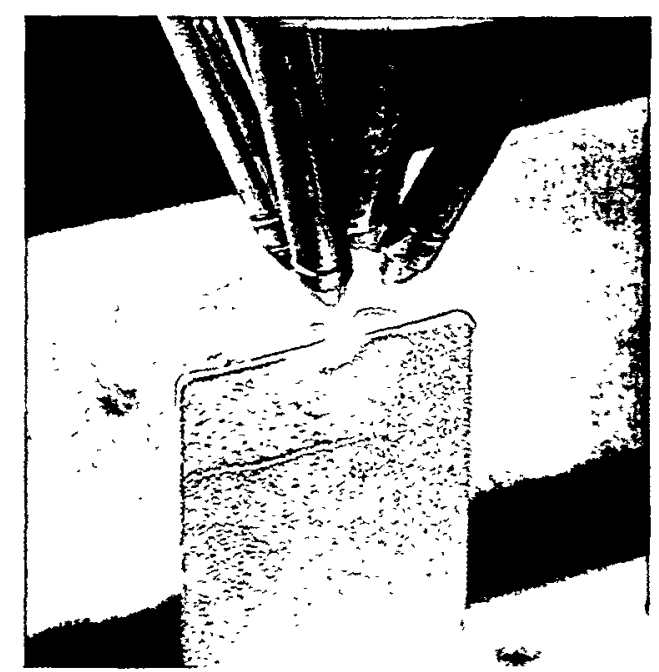

(b) In-situ wall fabrication. 


\section{DISCLAIMER}

This report was prepared as an account of work sponsored by an agency of the United States Government. Neither the United States Government nor any agency thereof, nor any of their employees, make any warranty, express or implied, or assumes any legal liability or responsibility for the accuracy, completeness, or usefulness of any information, apparatus, product, or process disclosed, or represents that its use would not infringe privately owned rights. Reference herein to any specific commercial product, process, or service by trade name, trademark, manufacturer, or otherwise does not necessarily constitute or imply its endorsement, recommendation, or favoring by the United States Government or any agency thereof. The views and opinions of authors expressed herein do not necessarily state or reflect those of the United States Government or any agency thereof. 


\section{DISCLAIMER}

Portions of this document may be illegible in electronic image products. Images are produced from the best available original document. 
The specific laser metal deposition technique used for this study is the Laser Engineered Net Shaping (LENS) process [1-5]. Figure 1a shows a schematic of the LENS process. A component is fabricated by focusing a laser beam onto a substrate while simultaneously injecting metal powder particles to create a molten pool. The substrate is moved beneath the laser beam in the $\mathrm{X}-\mathrm{Y}$ plane to deposit a thin cross section, thereby creating the desired geometry for each layer. After deposition of each layer, the powder delivery nozzle and focusing lens assembly are incremented in the positive Z-direction, thereby building a three dimensional component layer additively. Figure $1 \mathrm{~b}$ shows the deposition of a single pass wall in 316 stainless steel. LENS components have been fabricated from various alloys including stainless steel, tool steel, nickelbased super alloys, and titanium.

Any LENS fabricated component has a complex thermal history. It is important to understand the bulk and transient thermal behavior to reproducibly fabricate parts. The ultimate intent is to monitor the thermal signatures and to incorporate sensors and feedback algorithms to control part fabrication. With appropriate sensors and feedback, the geometric properties (accuracy, surface finish) as well as the materials' properties (e.g. strength, ductility) of a component can be designed into the part through the fabrication parameters.

To advance direct fabrication capabilities, the LENS process must be able to accommodate a wide range of materials and deposition styles. Over the past few years, we have built up an extensive material database to understand the range of materials processable by LENS. However, because LENS is a precision, point by point, fabrication process, we have expanded the deposition capability to include composites and graded structures [6]. Therefore, the designer can tailor physical properties critical to component performance. Examples include graded deposition for matching coefficient of thermal expansion between dissimilar materials, layered fabrication for novel mechanical properties, and new alloy design where elemental constituents and/or alloys are blended to create new materials.

In this paper, we will discuss our efforts to understand, model, and control microstructural evolution and material properties. We will also show advanced capabilities that are possible with a precision deposition process to tailor and enhance performance.

\section{MATERIAL PROPERTIES}

\section{Material Database}

As stated in the introduction, many alloys have been used to fabricate parts by LENS. Table I is a partial list of the room temperature mechanical properties for alloys ranging from stainless steels to titanium to nickel-based alloys. In most cases, the LENS properties are as good as if not better than the traditionally fabricated material. For stainless steel 316 (SS316), the yield strength is double that of wrought, while retaining a ductility of nearly $50 \%$. This is most likely due to Hall-Petch grain size refinement, where finer grain sizes results in higher yield strengths. Typical LENS-processed grain sizes range from 1-10 microns, where traditional wrought material is around 40 microns. At 40 microns, this translates to a yield strength of 30 $\mathrm{ksi}$, versus a 1 micron grain size should be equivalent to a yield strength $67 \mathrm{ksi}$ [7]. As-process LENS SS316 has a yield strength of $63 \mathrm{ksi}$, indicating that grain size refinement is controlling strength properties. 
Table I: Room temperature mechanical properties for various alloys fabricated by LENS. LENS properties are from as-process parts except where noted (*annealed, ** solution treated + annealed). LENS properties are compared to wrought material except when heat treated (HT), and properties are compared to same HT for traditional processing.

\begin{tabular}{|lccccccc|}
\hline MATERIAL & \multicolumn{2}{c}{$\begin{array}{c}\text { UTS } \\
\text { (KSI) }\end{array}$} & \multicolumn{2}{c}{$\begin{array}{c}\text { YTS } \\
\text { (KSI) }\end{array}$} & \multicolumn{2}{c|}{$\begin{array}{c}\text { EI } \\
\text { Wrought }\end{array}$} \\
SS 316 & 85 & 110 & 34 & 63 & 50 & 46 \\
SS 304L & --- & 95 & 40 & 47 & 55 & 70 \\
H-13 & 250 & 247 & 210 & 212 & 12 & $1-3$ \\
Ti-6AI-4V* & 135 & $130-145$ & 124 & $120-140$ & 10 & $1-16$ \\
IN718** & 200 & 203 & 168 & 162 & 20 & 16 \\
IN 625 & 121 & 135 & 58 & 89 & 37 & 38 \\
IN 600 & --- & 106 & --- & 62 & -- & 40 \\
\hline
\end{tabular}

\section{Effect of Layered Deposition}

For LENS components that will be used in the as-processed state, it is important to understand the effect of layered deposition and the many layer interfaces on the resulting mechanical properties. In the worst case, the layers are not well fused during fabrication, forming large pores, resulting in poor mechanical properties. But for fully dense material, it is necessary to determine the effect of the layered deposition on resulting performance. This will be important as more complex schemes are used to deposit material (e.g. multi-axis).

Simple sample geometries were chosen where the tensile direction is either parallel $(\mathrm{H})$ or perpendicular (V) to the layers. Table II shows the results for two stainless steel alloys and two nickel superalloys. The stainless steel alloys show the greatest effect of the layered deposition, where the strengths are lower for the vertical samples. This is most likely due to stress state condition where the layers are perpendicular to the pull direction and any imperfections will initiate fracture. Inspection of the fracture surfaces show fracture initiation occurs at a layer interface [8]. However, microstructural inspection does not reveal any defects or other features at the interface that would result in this behavior. The yield strengths are much higher for the horizontal samples, with a tradeoff in ductility. The horizontal specimens do show secondary cracks forming at the interface, further indicating that there is some sort of weak microstructure at the interface. Further microstructural analysis is required to understand the effect of the interfaces on resulting properties.

The nickel superalloys show little effect of the layered deposition, and variations in properties are more likely a result due to the small sampling of parts. It should be noted that 
many LENS parts are post-heat treated, and after a solution heat treat, the layered deposition structure completely disappears.

Table II: A comparison of build direction on as-processed room temperature tensile properties for two stainless steel and two nickel alloys.

\begin{tabular}{|c|c|c|c|c|}
\hline & MATERIAL & $\begin{array}{l}\text { UTS } \\
\text { (KSI) }\end{array}$ & $\begin{array}{c}\text { YTS } \\
\text { (KSI) }\end{array}$ & $\begin{array}{c}\mathrm{El} \\
(\%)\end{array}$ \\
\hline \multirow[t]{2}{*}{ V } & SS 316-V & 115 & 65 & 66 \\
\hline & SS $316-H$ & 117 & 86 & 30 \\
\hline & SS 304L-V & 95 & 47 & 70 \\
\hline & SS $304 \mathrm{~L}-H$ & 103 & 65 & 59 \\
\hline & IN 625-V & 135 & 89 & 38 \\
\hline & IN $625-H$ & 136 & 75 & 37 \\
\hline & IN $690-\mathrm{V}$ & 88 & 56 & 45 \\
\hline & IN 690-H & 108 & 63 & 48 \\
\hline
\end{tabular}

\section{Effect of Process Parameters}

One of the main goals of this research is to determine the effect of various process parameters on resulting material properties. With an understanding of their effect, we hope to predict and tailor the final performance behavior. An initial set of experiments was performed using H13 tool steel. Simple hollow boxes (shell build), one line wide, were fabricated with the following dimensions and deposition parameters:

Size: $101.6 \mathrm{~mm} \times 101.6 \mathrm{~mm} \times 152.4 \mathrm{~mm}$

Layer increment $=250 \mu \mathrm{m}$

Power: 200,250 and 300 Watts

Velocity: $5.92,7.62$, and $9.31 \mathrm{~mm} / \mathrm{s}$

By changing the power and velocity values, the deposition energy or thermal input is varied which could have an effect on final strength and ductility properties. Figure 2 shows the room temperature tensile results for nine power and velocity combinations. By modifying the deposition energy, one can tailor the strength and ductility values. For low energy input, through low power or high traverse velocity, the molten bead will solidify quickly resulting in high yield and ultimate tensile strength values. If the performance requires significant ductility or strain capability, parts should be fabricated at high energy input using high power and/or slow traverse velocity. As with many fabrication technologies, and in the case of $\mathrm{H} 13$ tool steel, one cannot achieve the highest strength and ductility values simultaneously. The designer must consider what are the performance priorities and match the processing conditions to achieve those properties. 


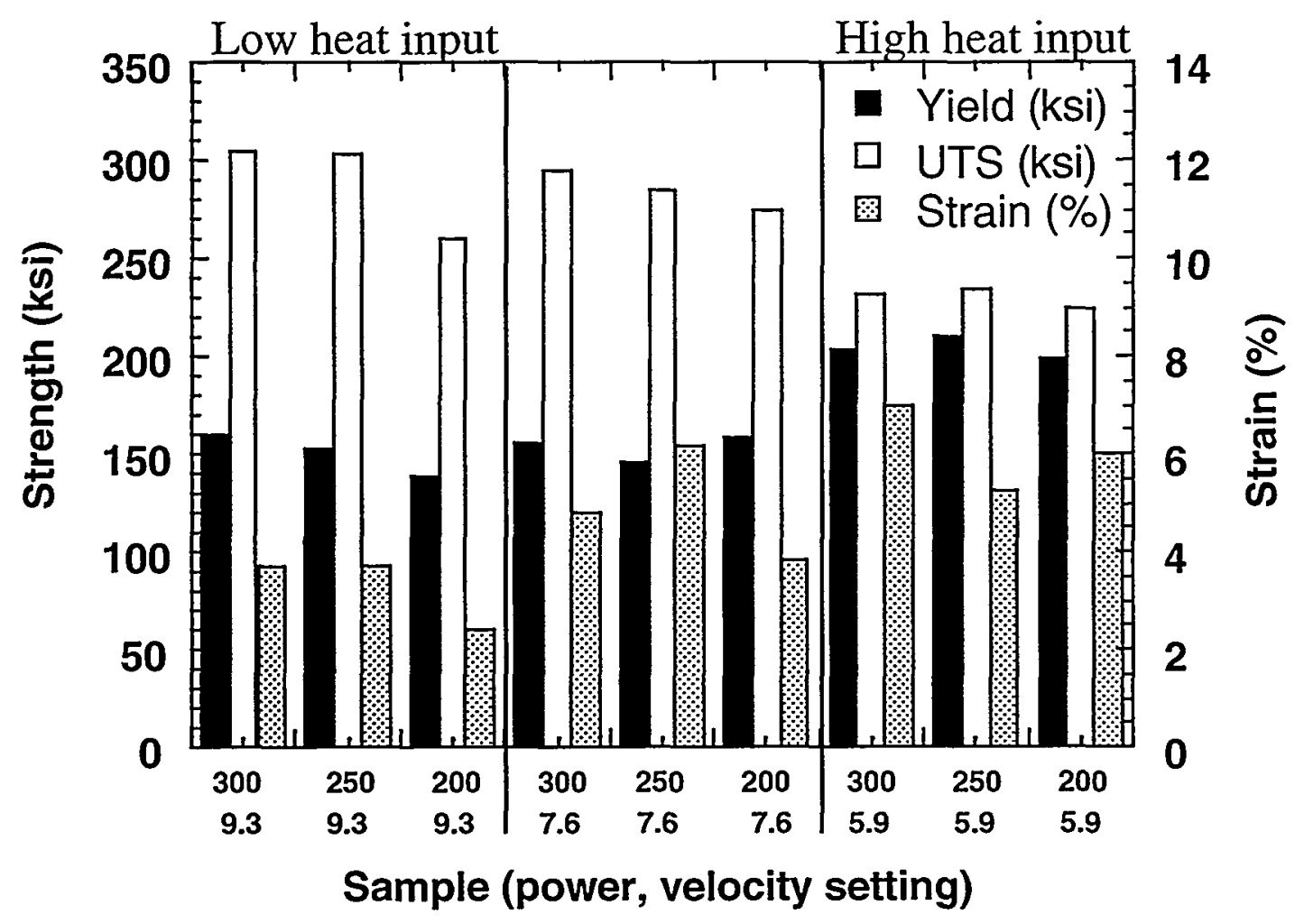

Figure 2: Comparison of room temperature tensile properties for $\mathrm{H} 13$ tool steel shell build samples fabricated at various power and velocity values.

\section{MATERIAL UNDERSTANDING AND CONTROL}

In order to understand the development of structure and properties in the solidified material, it is important to know the thermal gradients and cooling rates in and around the molten pool. These gradients control the morphology and scale of the first solid to form, and are a primary factor in determining the properties of the sample. Thermal measurements, microstructural studies, and modeling can be combined to develop process parameters to control microstructural development and tailor the properties of samples for particular applications.

\section{Thermal Imaging}

It is known intuitively that a thermal gradient exists across the molten pool and into the bulk material created by the LENS process. The nature and extent of this gradient has not been fully characterized. Since mechanical properties are dependent upon the microstructure of the material, which in turn is a function of the thermal history of solidification, an understanding of the temperature gradient induced by LENS processing is of special interest. It would be particularly beneficial to use non-invasive thermal imaging to measure the temperature profile and gradients and to use these thermal profiles in feedback control.

Preliminary experiments were conducted using ultra high speed digital imaging techniques [9-11] during LENS processing to provide insight as to the size of the molten pool and the thermal gradients in 316 stainless steel (SS316) samples fabricated using the LENS process. Figure 3 shows a typical view of the molten pool seen from the top. The image has 
been converted to temperature and colorized according to the adjacent scale. In the figure, the bead motion is from top to bottom, as signified by the thermal tail. The solidification interface, or pool area, at $1650 \mathrm{~K}$ is outlined and this is monitored in real time. Note there is an abundance of extra energy or superheat within the molten pool (greater than $250 \mathrm{~K}$ ), which will effect the thermal gradients and solidification microstructures.

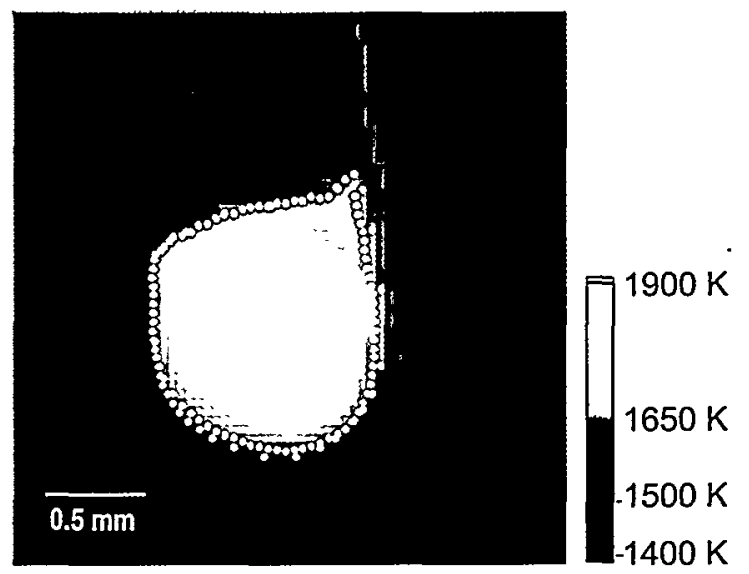

Figure 3: Image of molten pool during LENS processing. Dotted outline represents the solidification interface temperature, $1650 \mathrm{~K}$, for stainless steel 316.

The thermal profiles of the build reveal interesting non-linearities in the build process. Profiles were compiled for wall geometry builds as a function of laser power. These are presented in Figure 4 for SS316 alloy. The laser power for each profile is shown in the legend. The molten pool size increases with power up to $275 \mathrm{~W}$. Above $275 \mathrm{~W}$ the energy of the laser drives the pool temperature up without significant change in the length of the molten zone. Note also that the slopes of the temperature profiles outside the molten zone generally increase as the power decreases. Higher power results in more bulk heating of the sample away from the molten zone. This results in a lower cooling rate in the sample after solidification. For example, the cooling rate of the $275 \mathrm{~W}$ sample $0.5 \mathrm{~mm}$ from the solid-liquid interface is twice that of the $410 \mathrm{~W}$ sample. The initial scale of the microstructure, however, should be determined by the cooling rate at the solid-liquid interface.

A complete series of line builds was analyzed to determine the cooling rate at the solidliquid interface. These determinations are shown in Figure 5. At the interface the cooling rates are substantially higher at the low power levels and remain fairly constant at the higher powers. Thus, the highest quench rates are available at the lowest power, when the molten zone is small. As the laser power is increased, the quench rate at the interface settles at $1000-1500 \mathrm{~K} / \mathrm{s}$. All these results are for thin-walled features which show a great change in thermal gradients for changes in power. In contrast, for bulk solid fabrication, the cooling rates are not so varied. At the highest powers, the cooling rate is much lower, about $500 \mathrm{~K} / \mathrm{s}$, so that one may expect a more coarsened microstructure due to grain growth. With information about temperatures in and around the molten pool, pool size, and thermal gradients, we hope to utilize in-situ control to improve the capabilities of parts fabricated by LENS. 


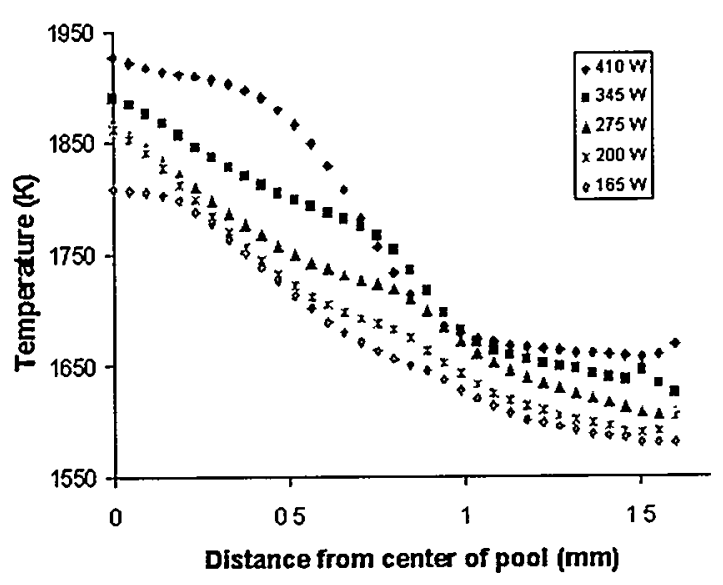

Figure 4: Thermal profiles from the center of the molten pool along the direction of translation for several different laser power settings.

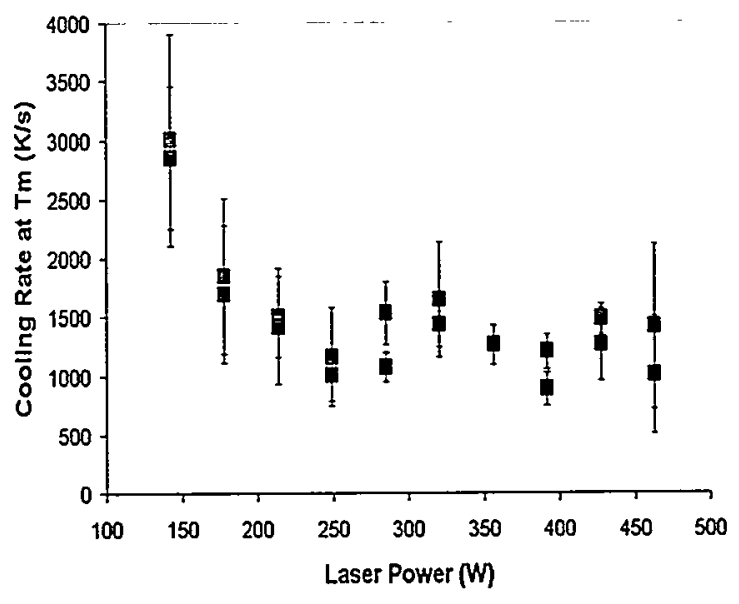

Figure 5: Cooling rates calculated from a large series of images as a function of laser power.

\section{In-situ Control of Thermal Signature using Visible Imaging}

With an understanding of the molten pool temperatures, thermal gradients, and steady state pool sizes, this information can be utilized to control the process. By matching the pool area to the specific thermal condition, one can extend the overhang capability in a 3-axis LENS system. Figure 6 shows a thin-walled hollow tube, two lines wide, with a $40^{\circ}$ overhang. Without any control over the thermal behavior or molten pool area, only a $20^{\circ}$ overhang is possible. Now, the pool area is matched to the geometric condition, in this case supported versus partially supported sections, to maintain a consistent, reliable build at $40^{\circ}$.

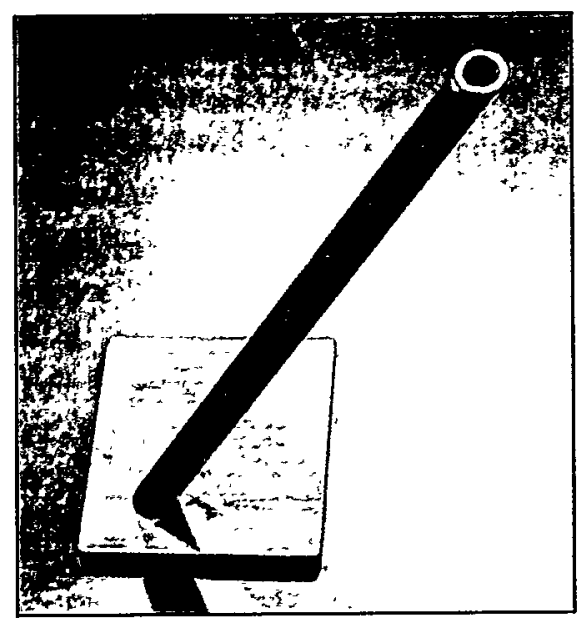

Figure 6: Photo showing advanced capability using closed loop control to fabricate double thick wall tube with $40^{\circ}$ angle.

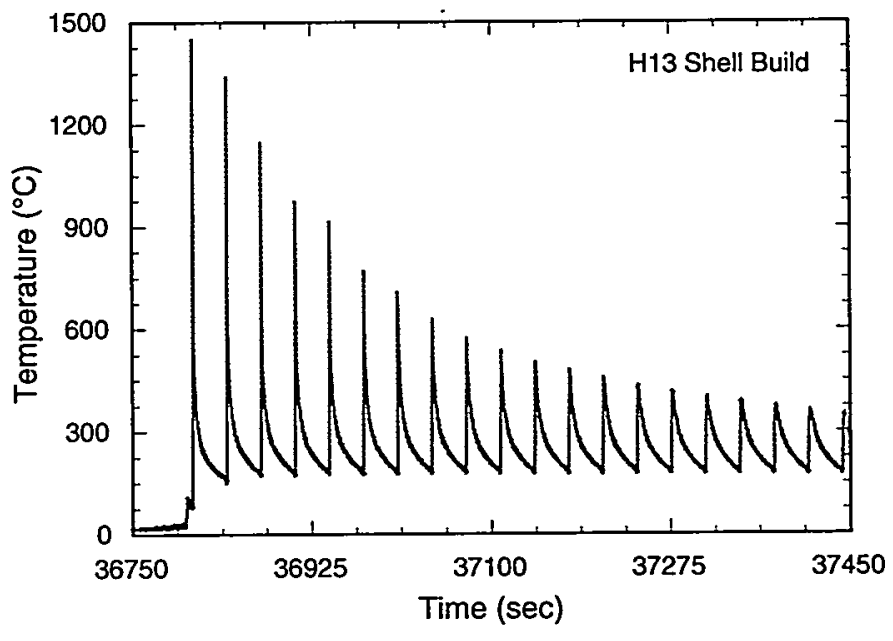

Figure 7: Temperature traces at one position as twenty layers are deposited on top of thermocouple inserted into H13 LENS shell build. 
A relatively easy way to obtain the thermal history during LENS processing is by inserting a thermocouple (TC) directly into the sample during fabrication [9]. Fine diameter (10 $\mu \mathrm{m}$ ) Type $\mathrm{C}$ thermocouple wire is used for measurements to ensure no reaction during deposition, and care was taken to insert the TC bead into the deposition zone for accurate temperature measurements. Figure 7 shows the in-situ temperature readings for twenty deposition layers from a representative thermocouple inserted during fabrication of $\mathrm{H} 13$ tool steel. Each peak represents the thermocouple response as the laser passes over or near the thermocouple, from initial insertion to subsequent layer depositions. The thermal excursions dampen out when either the energy source moves away from the thermocouple during fabrication of a layer or subsequent layers are deposited. After the initial peak in temperature, approximately $1500^{\circ} \mathrm{C}$, the heat is quickly conducted away in about 15 seconds to a nominal value of $150^{\circ} \mathrm{C}$ for the first layer. This initial thermal signature should result in a solidification process producing a high strength microstructure. Yet, for LENS processing, each subsequent pass reheats the previous layers, such that after the fifth layer is deposited, the initial layer still receives thermal excursions to $900^{\circ} \mathrm{C}$. Following thirteen deposition layers, the thermocouple nominally reads $500^{\circ} \mathrm{C}$. This complicated thermal cycling affects the material properties including residual stress and mechanical strength due to tempering or aging effects. This thermal behavior and effect on final properties is discussed in the next section.

\section{Microstructure Evolution in LENS Fabrication}

The characteristics of microstructural evolution in LENS fabrication can be complex due to the thermal transients and are dependent on the alloy system. However, some general considerations can be illustrated by discussion of a specific alloy system and the models which must be developed to describe the response of the alloy to processing. H13 tool steel provides a good example of an alloy system where there are several mechanisms for microstructural changes during processing. The LENS processing of this system has recently been described in more detail [12]. This is a commercially available secondary hardening alloy that is of significant industrial importance that, when conventionally heat treated, exhibits a martensitic structure strengthened by the formation of Mo and $\mathrm{Cr}$ containing alloy carbides.

Due to the layer additive nature of the LENS process, the thermal cycles associated with the LENS process can involve numerous reheating cycles. Thus, the goal of any assessment of microstructural evolution is to determine the response of the alloy to these cycles. For a shell build of $\mathrm{H} 13$, the peak temperature of the cycle provides a convenient means to classify the cycle and the response of the material. As shown in Figure 8, the build microstructure can be related to the $\mathrm{H} 13$ phase diagram, although it must be noted that, given the rapid heating and cooling rates, non-equilibrium conditions exist and the diagram can only be used as a general guide. The microstructure shown was taken from the final portion of the build, and can be separated into three different regions corresponding to peak temperature. Also shown is the height of the individual build passes.

Region I is composed of as-solidified H13 (last pass) and supercritically reheated (fully reaustenitized) material. Some segregation of alloying elements occurs as a result of partitioning during solidification, and little alloy element homogenization occurs due to the slow diffusion rates of substitutional alloying elements in austenite [13]. The exception is carbon for which the diffusivity is much more rapid and a uniform distribution is expected [13]. The supercritical region extends from the liquidus temperature to the ferrite + carbide two-phase region, which on 
I - Solidification/Supercritical

II - Intercritical heating

III - Sub-critical heating
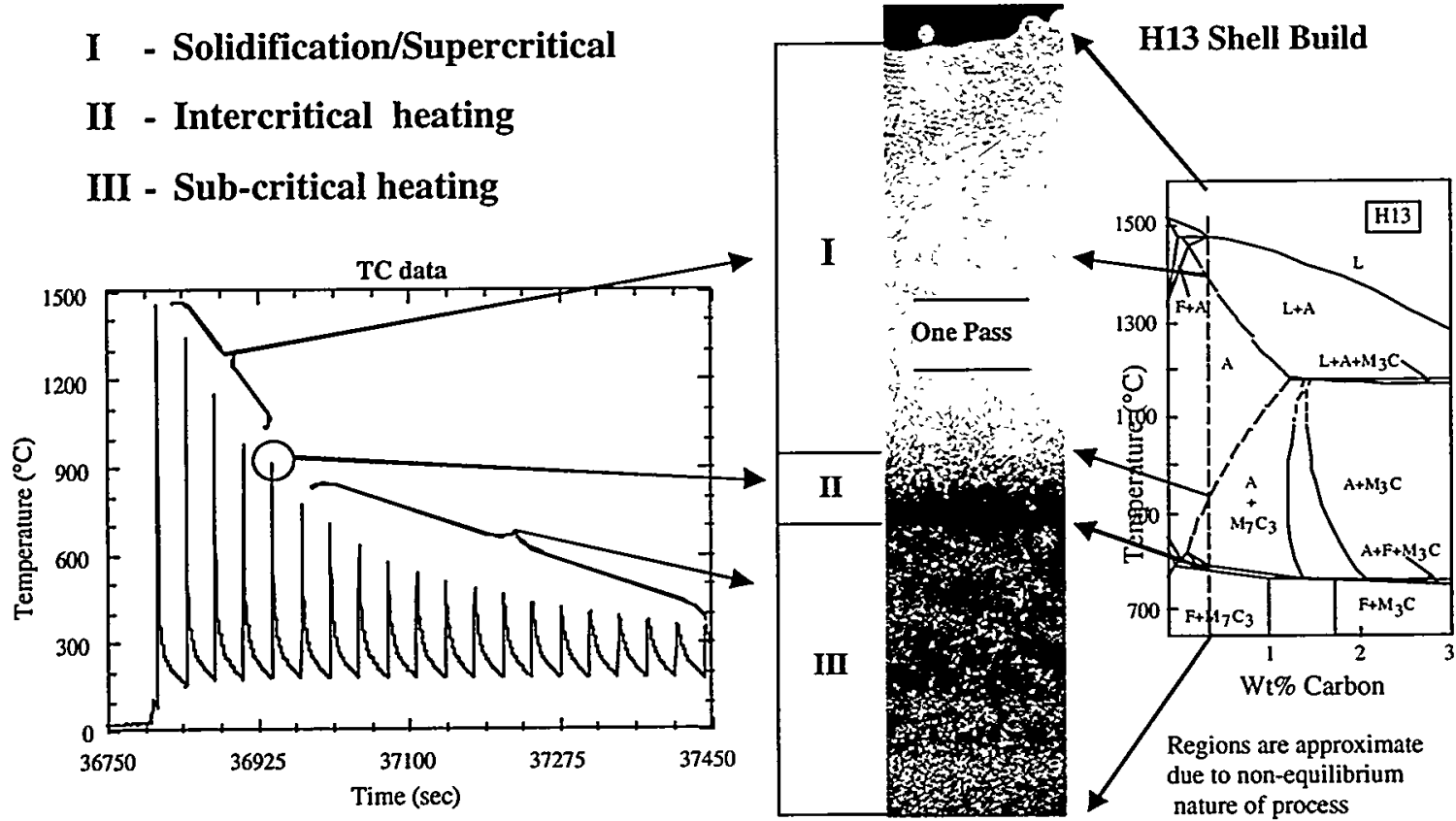

Figure 8: Correlation between measured thermal cycles, microstructure, and the phase diagram for $\mathrm{H} 13(0.04 \mathrm{wt} \% \mathrm{C})$ shell build. Three thermal regions are used to describe the behavior. The pass height for these conditions is approximately 0.25 $\mathrm{mm}$.

the equilibrium diagram is approximately $925^{\circ} \mathrm{C}$. The light etching material of the supercritical region is untempered martensite (hardness of $59 \mathrm{HRC}$ ) in which no carbides were detected using transmission electron microscopy (TEM).

Region $I I$ corresponds to material cycled into the intercritical two-phase and narrow three-phase regions shown on the diagram and corresponds to the fifth layer from the top of the build. This material had been previously cycled into the supercritical region, and is the uppermost dark etching region in Figure 8. It is interesting that the height of this region is close to that of a single pass height, and based on the phase diagram, would have contained a thermal gradient of roughly $150^{\circ} / 0.25 \mathrm{~mm}\left(\sim 600^{\circ} \mathrm{C} / \mathrm{mm}\right)$. For the thermal cycles shown, only the peak temperature of the fifth thermal cycle lies within this region. The region therefore consists of a mixture of carbides and martensite (formed from the austenite present at the peak temperature).

Region III contains the material that in addition to having experienced thermal cycles in the upper two regions, also experienced subcritical thermal cycles. For H13, the subcritical cycles can result in additional alloy carbide precipitation and/or carbide coarsening. The final microstructure (in the bulk of the build) therefore consists of martensite containing several types of alloy carbides. In this region, the hardness initially drops to a value of $54 \mathrm{HRC}$ and can further reduce depending on the processing and thermal history [12].

\section{Model Descriptions}

Given the qualitative descriptions for the microstructural changes which occur in each build region, it remains to develop kinetic models for the various mechanisms. Here again, it is important to recognize that these models are necessarily alloy dependent, and must reflect the principal strengthening mechanisms operative in the alloy. For $\mathrm{H} 13$, the supercritically heated region (Region $\mathrm{I}$ ) is relatively simple because the hardenability and cooling rates during the 
cycles are both high. Thus the microstructure after the supercitical cycles is essentially single phase fresh (untempered) martensite, although there may be some residual inhomogeneity in the alloy element distributions through the martensite. The solidification segregation of alloy elements can be estimated with knowledge of the solidification partition coefficients and conventional solidification models. The extent to which alloy element concentrations are homogenized during the supercritical passes can be estimated by using conventional diffusion calculations, but it is important to note that the diffusion equations must be solved over the thermal cycle(s) and therefore generally require numerical methods.

The microstructural changes occurring in Region II are perhaps the most severe and difficult to describe from a model perspective. During the intercritical cycles, the martensite present after the supercritical cycles transforms into ferrite, austenite, and carbides. At the temperatures involved (above $800^{\circ} \mathrm{C}$ ), the rate of this transformation is very high and difficult to analyze experimentally. Efforts are underway to develop kinetics models for these types of transformations (see, for example 14), but for the present overview it is sufficient to note that these models must describe the nucleation and growth of the austenite and carbides as well as the fractions of each constituent (austenite, ferrite and carbide) as they evolve during the temperature transient. Here again, the athermal nature of the process generally necessitates a numerical approach. It is important to note here that steels (and titanium alloys) are the only common commercial alloys that undergo these types of solid state phase transformations. As a result, other alloys, such as Ni-based superalloys, are therefore significantly less complex in terms of microstructural evolution.

Although the influence of the subcritical cycles is less pronounced than that of the intercritical cycles, the effects of these cycles can still be significant in terms of the microstructural evolution and resultant properties. For H13, the principal effects are those related to the precipitation and coarsening of alloy carbides. There are a number of approaches to describing these changes, and an example of one such approach is given in Ref. 12. In that work, hardness was selected as the property of interest, and a simple kinetic model describing the evolution of hardness during the subcritical cycling was developed. Inasmuch as many alloys of commercial interest are precipitation hardenable, models of this type are generally applicable to a wide range of alloys.

\section{EXPANDING MATERIAL DEPOSITION CAPABILITY}

One of the unique aspects to LENS is the point by point deposition style. With this type of deposition, it is possible to optimize the build parameters in order to improve fabrication.

Software has been developed to allow the designer to choose or correlate the build parameterssuch as layer thickness, hatch spacing, power, velocity, material, etc.- to part position. This is useful in many aspects: 1) deposition rate is tailored to feature size, 2) surface finish is controlled through outside border parameters, 3 ) feature size is correlated to deposition parameters to improve accuracy, and 4) multiple materials can be selected to tailor properties in particular part sections. Figure 9 is a simple example of tailoring the parameters for fabrication of a gear. Finer parameters (layer thickness and hatch) and a hardfacing alloy are used in the teeth section for good surface finish, feature definition, and wear properties. The inside section is an example of bulk deposition with a different alloy where the deposition rate is doubled and the alloy has more ductile properties. Therefore, the choices in deposition parameters and materials open a whole new capability in part fabrication. Results for layered and graded fabrication have been shown elsewhere for LENS [6]. 


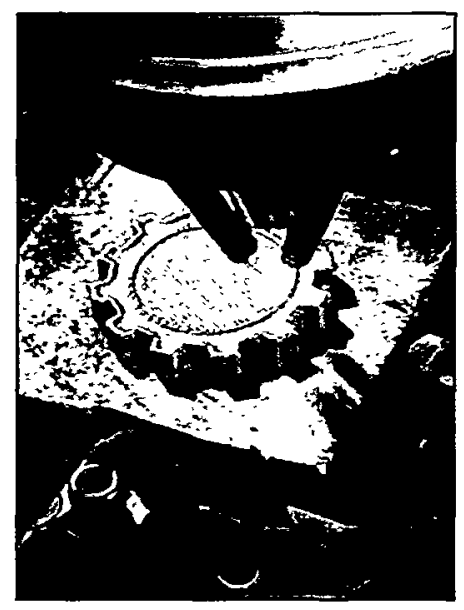

Figure 9: An example of tailored parameter and material fabrication for a gear section.

\section{SUMMARY}

In general, the evolution of microstructure and properties during LENS processing can be very complex. We are currently using visible and thermocouple techniques to determine the micro (molten pool) and macro (part) thermal history to gain an understanding of the LENS process. With in-situ monitoring, we have initiated process control through maintaining a setpoint for the molten pool area to extend the overhang capability. This control is coupled with new software to select deposition parameters that are tailored to the part geometry as well as the material performance through multi-material deposition. As we gain more knowledge of the process and resulting properties, we will further develop our models to predict and control the microstructural evolution.

\section{ACKNOWLEDGMENTS}

This work supported by the U. S. Department of Energy under contract DE-AC0494AL85000. Sandia is a multiprogram laboratory operated by Sandia Corporation, a Lockheed Martin Company, for the United States Department of Energy.

\section{REFERENCES}

1. M. L. Griffith, D. M. Keicher, C. L. Atwood, J. A. Romero, J. E. Smugeresky, L. D. Harwell, D. L. Greene, "Free Form Fabrication of Metallic Components using Laser Engineered Net Shaping (LENS)", Proceedings of the Solid Freeform Fabrication Symposium, August 12-14, 1996, Austin, TX, p. 125.

2. D. M. Keicher, J. A. Romero, M. L. Griffith, C. L. Atwood, "Laser Metal Deposition of Alloy 625 for Free Form Fabrication", Proceedings of the World Congress on Powder Metallurgy and Particulate Materials, June 16-21, 1996, Washington, D.C.

3. John E. Smugeresky, Dave M. Keicher, Joseph A. Romero, Michelle L. Griffith, Lane D. Harwell, "Using the Laser Engineered Net Shaping (LENS) Process to Produce Complex Components from a CAD Solid Model", Photonics West SPIE Proceedings - Lasers as Tools for Manufacturing, Volume 2993,1997, p. 91. 
4. E. Schlienger, D. Dimos, M. Griffith, J. Michael, M. Oliver, T. Romero, J. Smugeresky, "Near Net Shape Production of Metal Components using LENS", Proceedings of the Third Pacific Rim International Conference on Advanced Materials and Processing, July 12-16, 1998, Honolulu, HI, p. 1581.

5. C. L. Atwood, M. L. Griffith, M E. Schlienger, L. D. Harwell, M. T. Ensz, D. M. Keicher, M. E. Schlienger, J. A. Romero, J. E. Smugeresky, "Laser Engineered Net Shaping (LENS): A Tool for Direct Fabrication of Metal Parts", Proceedings of ICALEO '98, November 16-19, 1998, Orlando, FL, p. E-1.

6. M. L. Griffith, L. D. Harwell, J. A . Romero, E. Schlienger, C. L. Atwood, J. E. Smugeresky, "Multi-Material Processing by LENS", Proceedings of the Solid Freeform Fabrication Symposium, August, 1997, Austin, TX, p.387.

7. B.P. Kashyap, K. Tangri, Acta metall. mater., Vol. 43, No. 11 pp. 3971-3981, (1995).

8. J. Philliber, J. Smugeresky, B. Somerday, M. Griffith, "Microstructure and Properties of LENS processed 304L Stainless Steel", Presented at the Annual meeting of TMS, Nashville, TN, March 13-15, 2000.

9. M. L. Griffith, M. E. Schlienger, L. D. Harwell, M. S. Oliver, M. D. Baldwin, M. T. Ensz, J. E. Smugeresky, M. Essien, J. Brooks, C. V. Robino, W. H. Hofmeister, M. J. Wert, D. V. Nelson, "Thermal Behavior in the LENS Process", Proceedings of the Solid Freeform Fabrication Symposium, August, 1998, Austin, TX, p. 89.

10. M. L. Griffith, M. E. Schlienger, L. D. Harwell, M. S. Oliver, M. D. Baldwin, M. T. Ensz, J. E. Smugeresky, M. Essien, J. Brooks, C. V. Robino, W. H. Hofmeister, M. J. Wert, D. V. Nelson, Journal of Materials Design, volume 20 number 2/3, June 1999, p 107-114.

11. W. Hofmeister, M. Wert, J. Smugeresky, J.A. Philliber, M. Griffith, and M Ensz, JOM, Vol. 51, No. 7, available from JOM-e online at www.tms.org/pubs/journals/JOM/9907/Hofmeister/Hofmeister-9907.html.

12. J. Brooks, C. Robino, T. Headley, S. Goods, and M. Griffith, "Microstructure and Property Optimization of LENS Deposited H13 Tool Steel", Proceedings of the Solid Freeform Fabrication Symposium, August, 1999, Austin, TX, p.375-382.

13. J. A. Brooks, M. I. Baskes, and F. A. Greulick, Metall. Trans. A, 22A, (1991), pp. 915-925.

14. R. C. Dykhuizen, C. V. Robino, and G. A. Knorovsky, Metall. and Mat. Trans. B, 30B, (1999), pp. 107-117. 